\title{
BLOOD VOLUME PRECEDING AND FOLLOWING SPLENECTOMY IN HEMOLYTIC ICTERUS AND SPLENIC ANEMIA ${ }^{1}$
}

\author{
By HERBERT Z. GIFFIN AND GEORGE E. BROWN
}

With the Technical Assistance of Grace M. Roth

(From the Division of Medicine, The Mayo Clinic, Rochester)

(Received for publication December 26, 1928)

Very little investigative work has been published concerning the relationship of the spleen to blood volume. Barcroft, Harris, Orahovats, and Weiss allot to the spleen a function that correlates well with its anatomic structure. They demonstrated that the spleen acts as a reservoir in the normal resting animal, and that blood is expressed into the general circulation as a result of stimulation to a need for oxygen. The presence of a storage function is further demonstrated by the observation that carboxyhemoglobin disappears less rapidly from the spleen than from the general circulation, indicating that hemoglobin is, under normal conditions, stored in the spleen. These workers demonstrated the greater susceptibility of the splenectomized animal to carbon monoxide intoxication. Cruickshank's experiments on the cat indicate that the capacity of the spleen is from 2 to 5 per cent of the blood volume when calculated by fluctuations in hemoglobin and in changes in the volume of the spleen.

Observations concerning the spleen and splenectomy in relation to blood volume in man have not been found in the literature. The studies carried out previously have dealt largely with variations in the concentration of the erythrocytes and the hemoglobin, the morphology, and the chemistry of the blood. We know that splenectomy is curative in certain diseases and markedly beneficial in others, and definitely untoward effects attributable to splenectomy have not been observed in man, although there has been some question as to whether a factor of safety is removed by this operation.

${ }^{1}$ Read by title at the meeting of the American Society for Clinical Investigation, Washington, D. C., April 28, 1928. 
Our study was undertaken to determine: (1) the blood volume and plasma volume in patients suffering from certain diseases associated with splenomegaly, (2) the effects of splenectomy on the blood and plasma volume, and (3) whether in certain forms of splenomegaly the anemia is apparent rather than actual. The cases selected for this study fall into four groups:

number of cases

2. Primary splenomegaly without anemia:

Preceding splenectomy $\ldots \ldots \ldots \ldots \ldots \ldots \ldots \ldots \ldots \ldots \ldots \ldots, \ldots \ldots \ldots$

Following splenectomy $\ldots \ldots \ldots \ldots \ldots \ldots \ldots \ldots \ldots \ldots \ldots$

3. Hemolytic icterus: Preceding splenectomy $\ldots \ldots \ldots \ldots \ldots \ldots \ldots \ldots \ldots \ldots \ldots \ldots \ldots$

Following splenectomy $\ldots \ldots \ldots \ldots \ldots \ldots \ldots \ldots \ldots \ldots$

4. Splenic anemia:

Preceding splenectomy. . . . . . . . . . . . . . . . . . . . . .

Following splenectomy $\ldots \ldots \ldots \ldots \ldots \ldots \ldots \ldots \ldots \ldots \ldots \ldots \ldots \ldots \ldots$

The dye method was used to determine the blood volume and plasma volume. Congo-red was employed and three to four minutes allowed for the mixing time. Determinations were made under resting conditions without breakfast (8).

It has been shown in anemia that with a decrease in the hemoglobin and cell volume there is usually an increase in plasma volume. This is doubtless a compensatory phenomenon designed to maintain an adequate volume of circulating blood. The increase of plasma varies in different forms of anemia; according to Rowntree and Brown, it is absent or slight in the anemia of glomerulonephritis with edema and in the anemia associated with myxedema and Addison's disease. In this connection we have employed the term "replacement index" to represent the ratio of the percentage increase in plasma to the percentage decrease in cell volume.

For example, if the plasma volume is $61 \mathrm{cc}$. for each kilogram (normal $51.2 \mathrm{cc}$.) there would be an increase of $9.8 \mathrm{cc}$. $(19$ per cent). If the cell volume is $21 \mathrm{cc}$. for each kilogram (normal $36.5 \mathrm{cc}$.) there would be a decrease of $15.5 \mathrm{cc}$. ( 42 per cent). The ratio is $\frac{20}{4} \frac{0}{2}=0.45$; the replacement index is 45 . This indicates roughly that for every 100 cc. loss in cell volume there is approximately an increase of 45 cc. in plasma. 
NORMAL SUBJECTS

Dreyer and Ray have maintained that blood volume is a function of surface area rather than of body weight. We have, therefore, expressed our data according to both surface area and body weight and the statistical treatment of these data has shown a slightly higher correlation of volume to surface area then to body weight in normally built subjects.

The results obtained in seventy-four normal adult subjects (fortynine males and twenty-five females) have been reported by Rowntree and Brown. The ages varied from. seventeen to sixty-three years. The mean weight was $65.9 \mathrm{kgm}$. The mean value for the blood volume for each kilogram of body weight was $87.7 \mathrm{cc}$. (with a range of from 70 to $100 \mathrm{cc}$. in 98 per cent of the cases). The mean value for the plasma volume was $51.2 \mathrm{cc}$. (with a range of from 42 to $60 \mathrm{cc}$.). The mean value for the cell volume was $36.5 \mathrm{cc}$. for each kilogram. The mean value for the blood volume for each square meter of surface area was $3278 \mathrm{cc}$. For the plasma volume it was $1920 \mathrm{cc}$. for each square meter of surface area. The mean value for circulating hemoglobin was 13.8 grams for each kilogram of body weight, or 508 grams for each square meter of surface area. The cells by hematocrit were 41 per cent ${ }^{2}$ by the dry oxalate method, and the hemoglobin for each 100 cc. was 15.7 grams. These values closely approximate those obtained by Keith, Rowntree and Geraghty in their original report based on eighteen subjects. Many of the normal subjects varied considerably from the accepted average weight for height and age, but could not be classified as underweight or obese. When a classification of this group was made on the basis of a 10 per cent variation above or below the average standard for height and age, the mean values for the blood volume and plasma volume were only slightly different.

\section{PRIMARY SPLENOMEGALY WITHOUT ANEMIA}

Cases of primary splenomegaly without anemia, when all etiologic factors have been excluded, such as syphilis, malaria, hemolytic icterus,

${ }^{2}$ In subsequent work it has been found that hematocrit values obtained by the dry oxalate method should be corrected by the addition of 3.4 per cent. Therefore, 41 per cent, as used here, should read 44.4 per rent. 


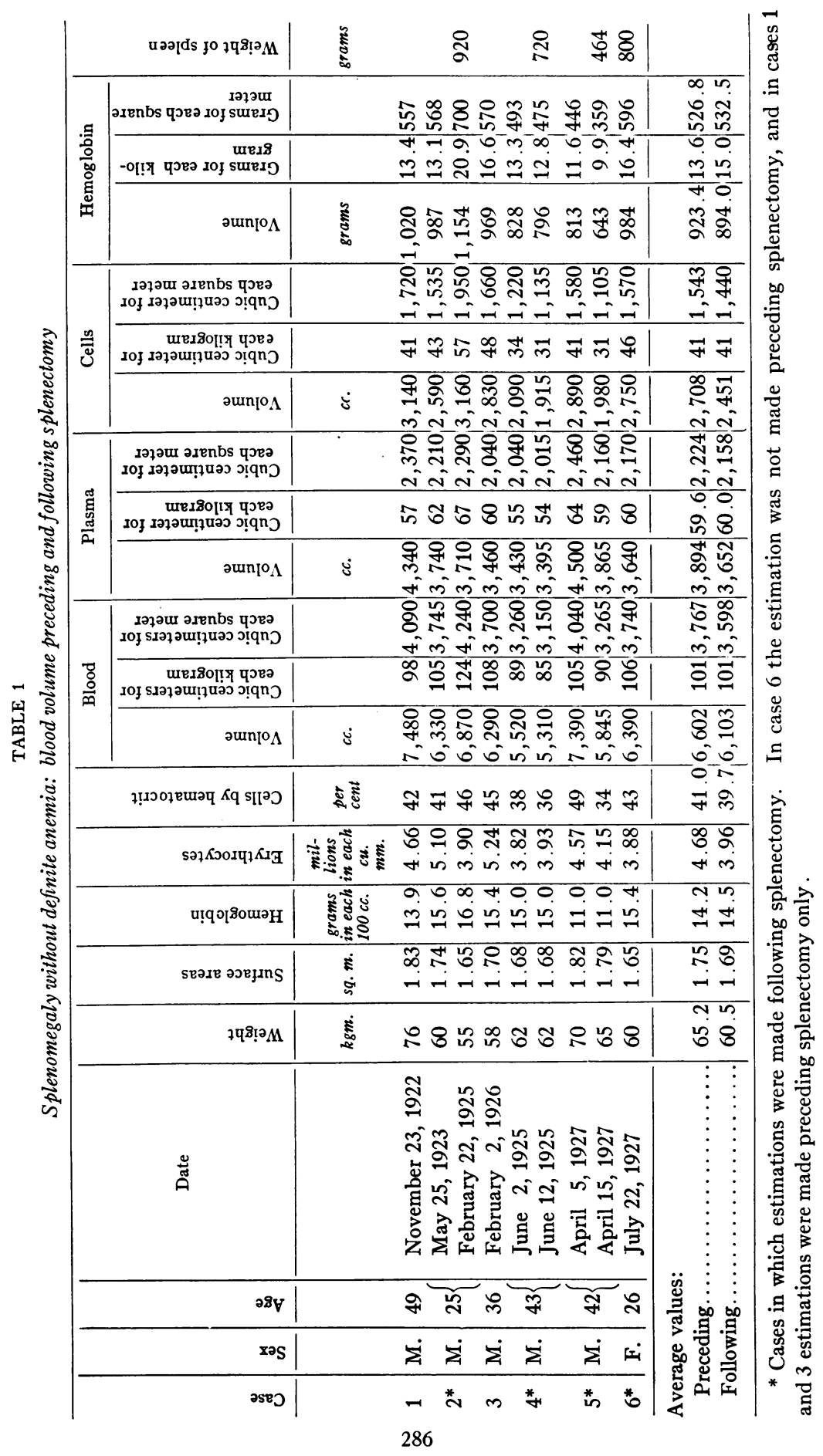


chronic infectious splenomegaly and various blood dyscrasias, have ordinarily been regarded as potential splenic anemia in the pre-anemic stage, and the splenic enlargement has been the outstanding clinical feature.

There were six cases in this group. Three were studied both before and after splenectomy. Two cases were studied preceding splenectomy and one case only after the operation. The results of these studies are shown in table 1.

Comment. The blood volume preceding splenectomy was $101 \mathrm{cc}$. and the plasma volume was $59.6 \mathrm{cc}$. These values are high. While the ratio of cell to plasma volume, as denoted by the hematocrit value of 41 per cent, was normal. This state has also been disclosed in cases of chronic passive congestion and in arteriovenous fistula, conditions in which a compensatory increase in the volume of circulating blood seems to be necessary for circulatory efficiency. This leads to the possibility that in primary splenomegaly without anemia, the increased. circulatory bed due to the splenomegaly and enlarged blood vessels necessitates a larger blood volume for circulatory needs.

The comparison of the average values of the two groups of cases before splenectomy and after splenectomy does not show significant change in blood volume, plasma volume or in the percentage of cells by hematocrit. In case 5 , with an interval of nine days, there was a decrease of 20 per cent in total blood volume and of 3 per cent in plasma volume. Since the weight decreased $5 \mathrm{kgm}$., the changes in volume for each kilogram were not so marked. This could be ascribed to operation and loss of blood. The large blood volumes in the cases with long intervals, one year and one and a half years after splenectomy, are probably more significant; these patients have a large volume of normal blood, an unusual condition in subjects of normal build.

\section{HEMOLYTIC ICTERUS}

The clinical features of hemolytic icterus are well known. The fundamental process is abnormally active hemolysis and the pathologic basis is probably chiefly concerned with increased fragility of the erythrocytes and microcytosis (Giffin). In the diagnosis of hemolytic icterus care must be taken to exclude cirrhosis of the liver with 


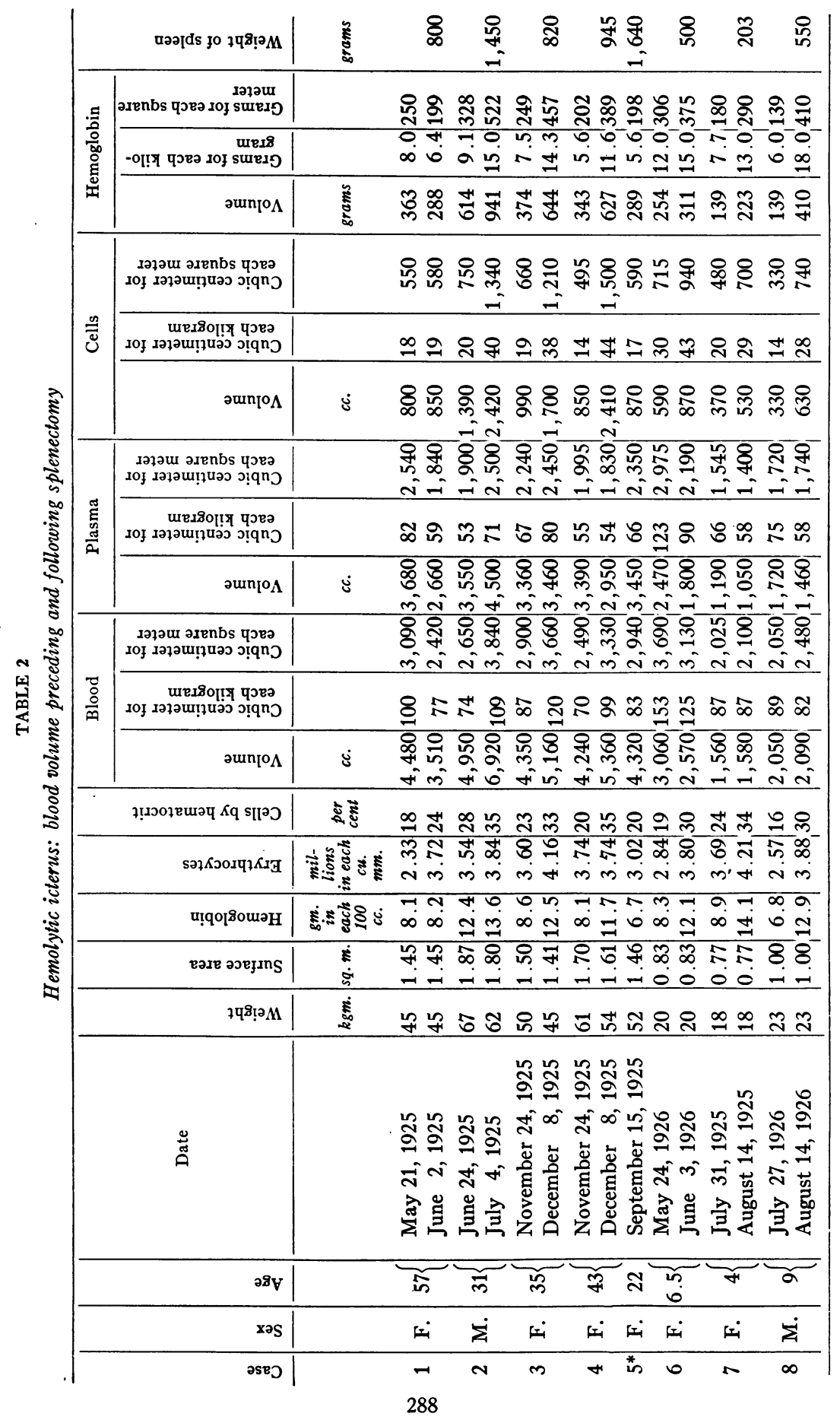




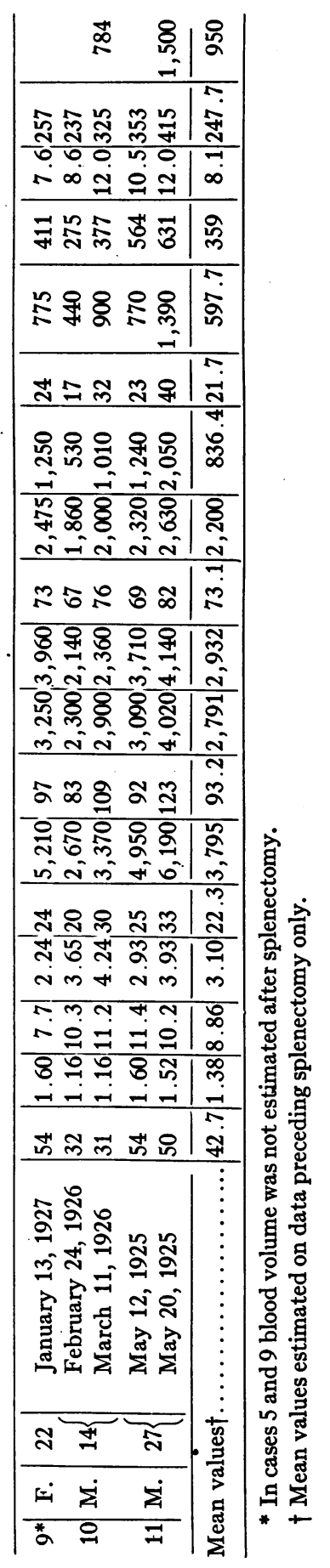


secondary hemolytic characteristics. Splenectomy is a curative measure. Following operation the jaundice disappears, the excessive hemolysis ceases and, in some instances at least, the erythrocytes become less fragile. As Moynihan stated: "The spleen, if not the exclusive cause or seat of the disease, exerts the profoundest influence on its pathogeny."

Preceding splenectomy. Eleven cases of hemolytic icterus were studied (table 2). The body build in this group was subject to wide variation; none of the patients were overweight, but the younger patients were underweight. Studies of the blood volume were made one or two days preceding operation, and from nine to seventeen days following operation. Anemia was present in all of the cases. The patient with a blood volume of $153 \mathrm{cc}$. was the only one with a volume above the upper range of normal; she was an emaciated girl aged six and a half years, and according to surface area the blood volume was less than the normal mean. According to surface area the mean plasma volume for the entire group was $2200 \mathrm{cc}$. for each square meter, about 15 per cent higher than the normal mean.

That anemia was actually present is shown by the amount of circulating hemoglobin. The mean value for hemoglobin was 8.1 grams for each kilogram of body weight (normal 13.8 grams). The mean value for the cell volume was $21.7 \mathrm{cc}$. for each kilogram (normal $36.5 \mathrm{cc}$.), a decrease of $14.8 \mathrm{cc}$. (45 per cent). The mean value for the plasma volume was $73.1 \mathrm{cc}$. (normal $51.2 \mathrm{cc}$.), an increase of 21.9 cc. (43 per cent). The ratio was, therefore, $\frac{48}{\frac{3}{5}}=0.95$. This replacement index of 95 is high, almost twice that seen in primary and simple secondary anemia.

The hemoglobin in grams and the blood volume when separately plotted against the weight of the spleen did not correlate. The cell volume calculated for each kilogram of body weight plotted against the weight of the spleen did not show definite correlation. There was a fairly high correlation of 0.87 between plasma volume and weight of the spleen.

Following splenectomy. Estimations were made from nine to seventeen days following splenectomy in nine of the eleven cases (table 2). The plasma volume according to body weight and surface area showed a smaller percentage variation since the body weight decreased 
after operation. The total hemoglobin volume increased in all but one case, the range of increase being from 57 to 327 grams, averaging

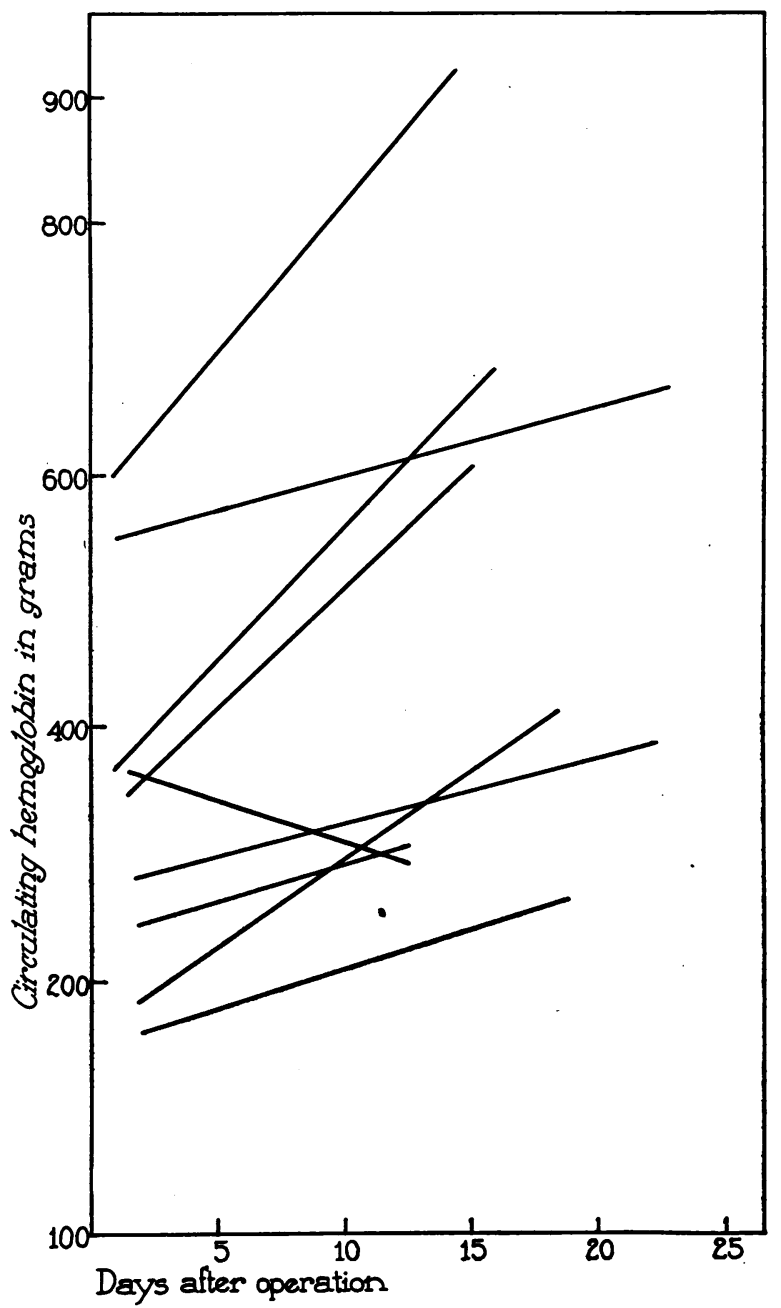

Fig. 1. Changes in the Circulating Hemoglobin in Cases Following SPLENECTOMY FOR HEMOLYTIC JAUNDICE

183 grams (fig. 1). The percentage of cells by hematocrit and the number of erythrocytes increased in every case, and the hemoglobin in grams for each $100 \mathrm{cc}$. showed a significant increase in all but two cases. 
Comment. The status of the blood volume in hemolytic icterus, according to mean values, is that of decreased cell volume with normal blood volume. The cell volumes and the hemoglobin volumes according to body weight and surface area were decreased, which is indicative of the existence of an actual rather than an apparent anemia. With the exception of one case, that of a child, the blood volume conformed closely to the normal range, which is 70 to $100 \mathrm{cc}$. for each kilogram. The plasma volume, however, was greatly increased, the increase amounting to a mean of 21.9 cc., 43 per cent for each kilogram above the normal mean. The replacement index was high, 95; . in other words, when compared to normal values the increase of plasma to replace the decrease in cells was almost complete. This indicates that in hemolytic icterus the replacement of the diminished cell volume by plasma is effective and adequate, much more so, in fact, than in primary anemia and simple secondary anemia without splenomegaly.

The increase in the blood volume and cell volume following splenectomy in cases of hemolytic icterus is most striking and correlates well with the clinical improvement following operation. In every case but one the cell volume increased significantly within three weeks and the actual volume of hemoglobin showed comparable changes, the increase averaging 183 grams. In case 2 (table 2) the increase in the blood volume was more than a third of the preoperative value, and the actual increase of hemoglobin was 327 grams in ten days, or over 30 grams a day. This increase of hemoglobin represents only the demonstrable increase of pigment and does not include the amount necessary to compensate for that which is normally destroyed. Figures for the normal amount of hemoglobin formed daily in man are not available. Whipple, Robscheit and Hooper have shown that in the dog after unit hemorrhages, the amount of hemoglobin regenerated depends largely on the type of diet. In one experiment with beef heart diet, 43 grams of hemoglobin were formed daily over a seven-day period.

The rate of recovery from anemia after splenectomy is not correctly shown in the concentration values for hemoglobin and erythrocytes. For example, in case 2 (table 2) following operation there was an increase of about 9 per cent in the grams of hemoglobin in each $100 \mathrm{cc}$. and a questionable increase in the number of erythrocytes. The 
increase in the blood volume, however, was 1970 cc. (40 per cent) half of which was cells. The increase in the actual volume of hemoglobin was 327 grams, or about 50 per cent. The plasma volume increased $940 \mathrm{cc}$. while the cell volume increased $1030 \mathrm{cc}$., that is, cells increased in greater proportion than plasma, thus affecting the ratio of cells to plasma.

Hooper, Robscheit and Whipple have shown that in the recovery from experimental anemia, the increased plasma volume caused by the anemia gradually disappears with the regeneration of cells. In the recovery from anemia in hemolytic icterus, the plasma volume decreased in five cases with the increase of cells, and increased in four cases.

The status of the blood volume as indicated by the mean value in a series of eleven cases of hemolytic icterus preceding splenectomy is that of decreased cells with normal volume. The anemia of hemolytic icterus is an actual rather than an apparent anemia and as the plasma volume increases to cause a slightly high blood volume a small amount of dilution occurs. The blood volume is maintained within a normal range since the replacement of cell volume by plasma is almost complete, as shown by a replacement index of 95 . Following splenectomy there is an immediate rapid increase in the cell volume and hemoglobin volume which is not adequately demonstrated by the ordinary clinical estimations for determining the concentration of hemoglobin and erythrocytes.

\section{SPLENIC ANEMIA}

Splenic anemia is a useful term to indicate a poorly defined clinical syndrome rather than a disease entity, and the diagnosis is chiefly made by exclusion. Cases included in this group have two features in common: primary splenomegaly, and a secondary type of anemia. Cases of questionable diagnosis are always present in a group of cases classified as splenic anemia, and the difficulties of arriving at conclusions concerning observations on the blood volume are correspondingly increased, especially in those cases in which secondary hepatic cirrhosis is present.

Preceding splenectomy. Estimations of blood volume were made preceding splenectomy in eighteen cases classified as splenic anemia, 


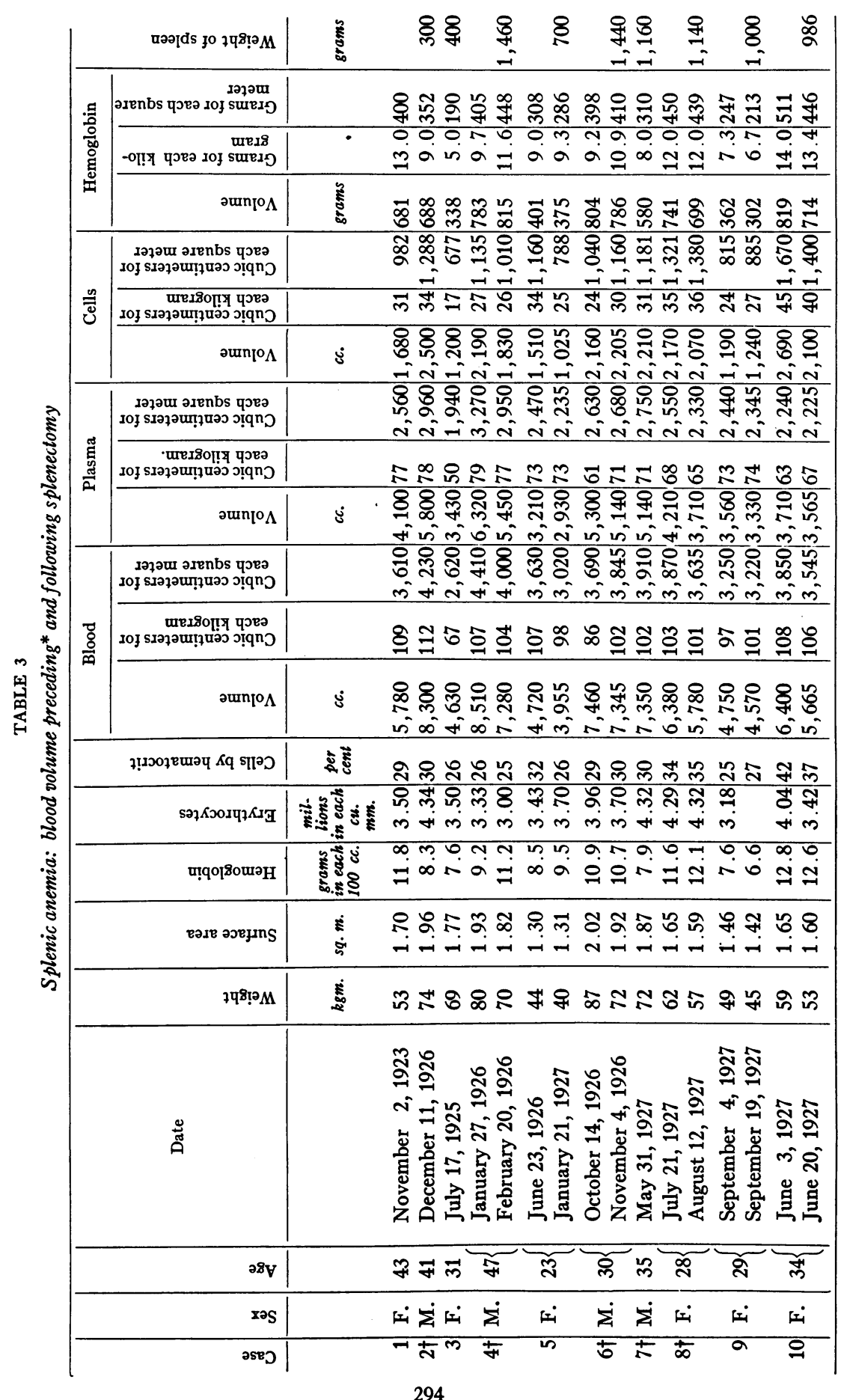




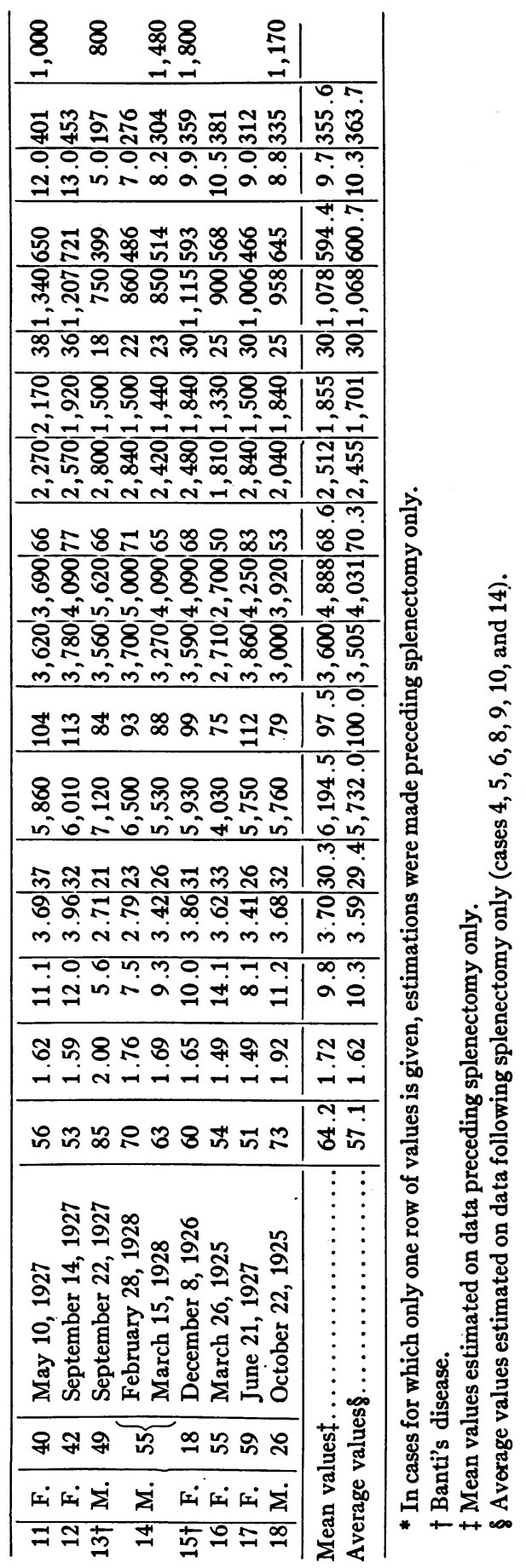


seven of the Banti type (table 3). It will be noted in table 3 that in the seven cases of the Banti type there was approximately the same high blood volume as that in the cases without advanced hepatic cirrhosis.

The body build of this group of patients was fairly uniform. None was obese or emaciated. The mean figure for body weight was $64.2 \mathrm{kgm}$.

Following splenectomy. In seven of the cases observations were made both before and after splenectomy. Estimations of blood volume were made from two to three weeks after operation (table 3).

Comment. The mean value for the blood volume according to the body weight and surface area is increased in splenic anemia approximately 10 per cent above the normal. This increase is largely due to plasma volume since the cell volume is reduced 18 per cent. The mean value for the plasma volume according to weight and area is approximately 30 per cent above normal. The plasma volume is much higher in splenic anemia than in the chronic secondary types of anemia and in pernicious anemia with comparable hemoglobin and cell values. This fact suggests the question whether the anemia is actual or whether dilution factors play a rôle causing apparent anemia. The circulating hemoglobin in grams for each kilogram preceding splenectomy was 9.7 grams, or for each square meter of surface area 355.6 grams compared with a normal of 13.8 grams and 508 grams, respectively. This would indicate that actual anemia exists which is diluted by the abnormally high plasma volume. The anemia is due both to dilution and to actual loss of hemoglobin. The plasma not only replaces the lost cell volume but increases to a point beyond the original blood volume. The replacement index is very high, as is demonstrated by the following calculation: A mean cell volume of $30 \mathrm{cc}$. for each kilogram, compared with a normal of $36.5 \mathrm{cc}$., is $6.5 \mathrm{cc}$., 17.8 per cent, less than normal; the mean value for the plasma volume of $68.6 \mathrm{cc}$. (normal $51.2 \mathrm{cc}$.) is $17.4 \mathrm{cc} ., 34$ per cent, above normal. The replacement index would then be $191\left(\frac{84}{17.8}=1.91\right)$. The replacement index as demonstrated in sixteen cases of secondary anemia was 42 and in ten cases of pernicious anemia was 30 .

The reason for the increase in plasma volume in cases of splenic anemia is not clear although there is a close correlation between the 
plasma volume and the weight of the spleen. It has been suggested that in the cases of enlarged spleen and a presumably active reticuloendothelial system the dye is removed from the blood with abnormal rapidity. Information on this point has been obtained by the following experiments:

1. In two cases of hemolytic icterus volume determinations were made on the operating table just prior to removal of the spleen. Twenty to thirty minutes after the injection of the dye, samples of blood were taken from the splenic artery, splenic vein and spleen pulp. It was found that the concentration of the dye in the three samples was exactly the same. These experiments seem to demon-

TABLE +

Percentage of variation in the plasma volume within six minutes after injection of the dye

\begin{tabular}{c|c|c|c|c}
\hline & \multicolumn{3}{|c}{ Time after injection } \\
\cline { 2 - 4 } Case & 2 minutes* & 3 minutes & 4 minutes & 6 minutes \\
\hline 1 & 100 & 100 & 100 & 100 \\
2 & & 100 & 101 & 107 \\
3 & 100 & 100 & 101 & 102 \\
4 & 100 & 100 & 100 & 104 \\
5 & 100 & 99 & 100 & 96 \\
6 & 100 & 97 & 100 & 100 \\
\hline
\end{tabular}

* The two-minute determination is taken as 100 per cent.

strate that the dye is not abnormally removed by the cells of the spleen in hemolytic icterus.

2. The rate of disappearance of the dye from the blood was ascertained by determining the plasma volume at periods of two, three, four and six minutes in a large series of normal subjects and in six cases of splenic anemia (table 4), demonstrates that an increased or abnormal rate of disappearance of the dye was not present in the cases of splenic anemia. Moreover, dye was not excreted in the urine within one hour after injection, as has been demonstrated in certain cases of nephrosis.

The effect of anemia on the increase in plasma volume was considered. Only rarely in cases of secondary anemia were high plasma volumes found. In thirty cases of primary and secondary anemia there 
was a moderate increase in the relative volume of plasma with mean values of 60 and $58 \mathrm{cc}$., respectively. This would indicate that the anemia is probably not the sole factor in the production of the high plasma volume in splenic anemia. It was demonstrated in the series of cases reported in the first portion of this paper that cases of splenomegaly without anemia also show a high plasma volume. It is possible, then, that a high plasma volume may be one of the fundamental changes in cases of splenic anemia, and that it may precede the development of anemia.

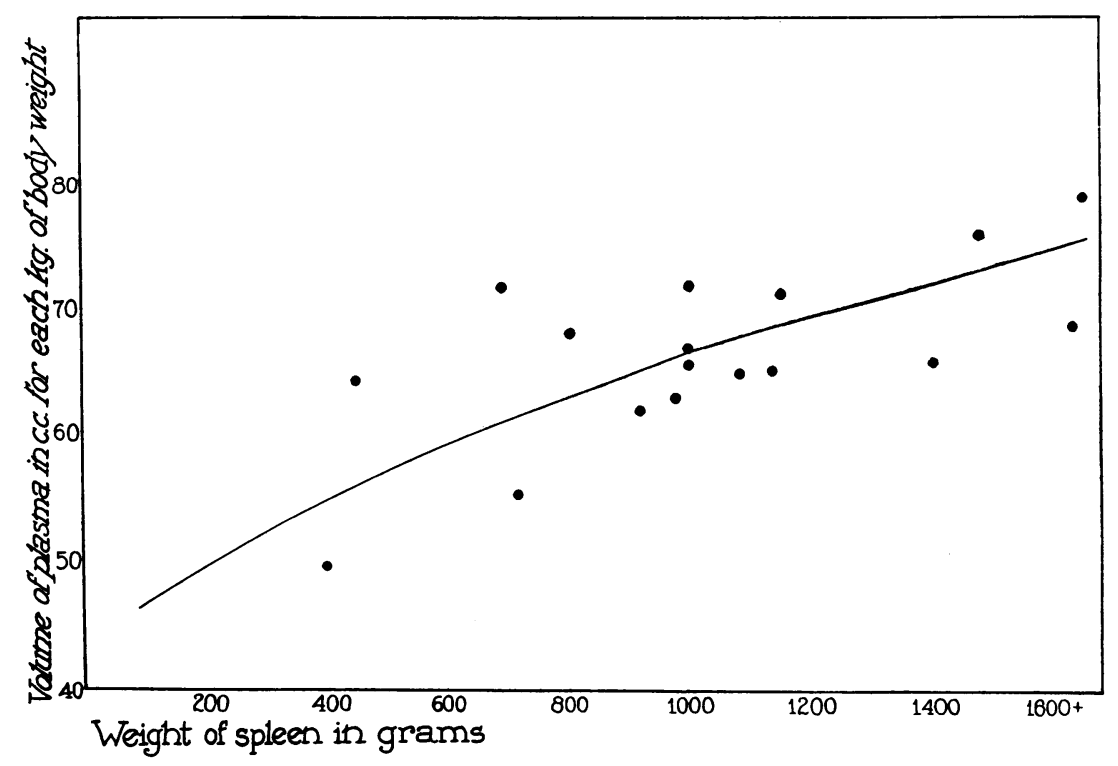

Fig. 2. Plasma Volume and Weight of Spleen in Splenic Anemia

Following splenectomy a decrease in the total volume of the circulating blood occurred in every case. This decrease was slight in one instance but definite in all the others. The maximal decrease was $1230 \mathrm{cc}$. and the average was $656 \mathrm{cc}$. The decrease in the total blood volume was more constant and marked than that occurring in the relative blood volume for each kilogram because of variations in body weight. On the basis of surface area a decrease occurred in all but one case. The plasma volume likewise decreased in every instance, with a range of decrease from 145 to $910 \mathrm{cc}$., the average decrease being 
442 cc. Slight increases and decreases occurred according to body weight. The cell volume decreased in five of the seven cases, but was significant in only three cases. In only two cases did the cell volume show an increase. The total amount of circulating hemoglobin in grams showed a decrease in five of the seven cases, averaging 50 grams.

The total blood volume for each kilogram of body weight was charted against the weight of the removed spleen. The curve shows a rough correlation between these factors. It is apparent that larger volumes of blood occurred in the cases in which the spleen was largest. A closer correlation is brought out when the plasma volume for each kilogram is plotted against the weight of the spleen. The curve approximates a straight line (fig. 2). Between the cell volume and the weight of the spleen definite correlation could not be demonstrated.

The moderate reduction in the blood volume after splenectomy in cases of splenic anemia would, at first thought, be attributed to loss of blood. The studies in these cases were made two and three weeks following operation; this interval would ordinarily be regarded as sufficient for adequate blood regeneration. There is great variation in the amount of blood lost at operation; in some cases it is negligible and in others large. There does not seem to be any correlation between the amount lost at operation and the decrease in blood volume. Likewise, the drop in the volume of blood after operation consists largely of plasma, indicating a readjustment following splenectomy. A relationship could not be established between the reduction in blood volume and plasma volume and the weight of the spleen; in fact, the patient (case 5, table 3) with the smallest spleen, showed the greatest decrease in blood volume. Surprisingly small amounts of blood were recovered from the enlarged spleens; the amount ranged from 100 to $500 \mathrm{cc}$. Either the contraction of the spleen eliminates much of the blood before it is removed, or its actual capacity is reduced, possibly because of fibrosis. One would infer from these observations that loss of blood due to removal of the spleen, although it may affect the results to a certain degree, does not account for all of the reduction in volume of blood, nor could it account for the disproportionate loss in the plasma volume and the relatively high plasma volumes remaining after splenectomy.

Summarizing these results in connection with splenic anemia, it has 
apparently been shown: (1) the plasma volume, and therefore the total blood volume, is high according to body weight in spite of a decreased volume of cells; (2) the increased plasma volume estimation is not due to an abnormal affinity of the cells of the spleen for the dye, to loss of the dye in the urine, or to an abnormally rapid rate of disappearance from the blood; (3) while the existence of anemia is usually a significant factor in the production of the high plasma volume, it is not the important or sole factor as it seems to be in cases of secondary anemia and pernicious anemia; (4) the enlarged spleen is probably an additional factor in the increase of plasma volume and total blood volume; even in splenomegaly without anemia the plasma volume is slightly increased, and (5) a fairly high correlation exists between the weight of the spleen and the plasma volume for each kilogram.

\section{SUMMARY}

The figures obtained in blood volume studies in seventy-four normal adult subjects reported elsewhere by Rowntree and Brown are approximately as follows: for both sexes, mean value for the blood volume for each kilogram of body weight; $87.7 \mathrm{cc}$; plasma volume for each kilogram, 51.2 cc.; cell volume, 36.5 cc.; circulating hemoglobin for each kilogram of body weight, 13.8 grams, and for each square meter of surface area, 508 grams; hemoglobin for each 100 cc., 15.7 grams, and cells by hematocrit, 41 per cent. On the basis of each square meter of surface area the values are approximately as follows: volume of blood, $3278 \mathrm{cc}$; volume of plasma, $1920 \mathrm{cc}$., and volume of cells, $1358 \mathrm{cc}$.

In cases of primary splenomegaly without anemia the mean value for the blood volume was increased to $101 \mathrm{cc}$, for each kilogram, the plasma volume was increased to $59.6 \mathrm{cc}$., and the ratio of the cells to plasma was normal. After splenectomy there was no significant change in the blood volume or in plasma volume, the values still remaining above normal.

In hemolytic icterus the blood volume was normal and the cell volume decreased; the replacement of the diminished cell volume by plasma was complete. After splenectomy there was an increase in blood volume and a very striking increase in the volume of cells and hemoglobin. These increases were much greater than were indicated by the ordinary estimations of hemoglobin and erythrocytes. 
In splenic anemia blood volume was increased and cell volume decreased. An increase in the plasma volume was found which could not be accounted for solely on the basis of anemia. The anemia was due both to dilution and actual loss of hemoglobin. Following splenectomy a moderate decrease, which was largely in the plasma volume, occurred in the total blood volume, yet the increased plasma volume persisted. A high correlation has been demonstrated for the relative plasma volume and the weight of the removed spleen.

Most of these observations were made within three weeks of the time of operation. The number of observations made at longer intervals subsequent to splenectomy have been too few to warrant discussion.

\section{BIBLIOGRAPHY}

1. Barcroft, J., Harris, H. A., Orahovats, D., and Weiss, R., J. Physiol., 1925, lx, 443. A contribution to the physiology of the spleen.

2. Cruickshank, E. W. H., J. Physiol., 1926, lxi, 455. On the output of haemoglobin and blood by the spleen.

3. Dreyer, G., and Ray, W., Proc. Roy. Soc. Lond., 1910, Series B, lxxxii, 545. The blood volume of mammals as determined by experiments apon rabbits, guinea-pigs and mice; and its relationship to the body weight and to the surface area expressed in a formula.

4. Giffin, H. Z., Surg., Gynec., and Obstet., 1917, xxv, 152. Hemolytic jaundice; a review of seventeen cases.

5. Hooper, C. W., Robscheit, F. S., and Whipple, G. H., Am. J. Physiol., 1920, liii, 263. Blood regeneration following simple anemia. V. The influence of Blaud's pills and hemoglobin.

6. Keith, N. M., Rowntree, L. G., and Geraghty, J. T., Arch. Int. Med., 1915, xvi, 547. A method for the determination of plasma and blood volume.

7. Moynihan, Berkeley, G. A., The spleen and some of its diseases. Philadelphia, W. B. Saunders Co., 1921.

8. Rowntree, L. G., and Brown, G. E., Blood volume in health and disease. (In press.)

9. Whipple, G. H., Robscheit, F. S., and Hooper, C. W., Am. J. Physiol., 1920, liii, 236. Blood regeneration following simple anemia. IV. Influences of meat, liver and various extractives alone or combined with standard diets. 